\title{
Effects of Vegetation Density and Arrangement on Sediment Budget in a Sediment-Laden Flow
}

\author{
Jin-Fu Li ${ }^{1}$, Samkele S. Tfwala ${ }^{2}$ (I) and Su-Chin Chen ${ }^{3, *}$ (1) \\ 1 Department of Soil and Water Conservation, National Chung Hsing University, Taichung 402, Taiwan; \\ dennis4607@hotmail.com \\ 2 Department of Geography, University of Swaziland, Kwaluseni M201, Swaziland; \\ samkelet@email.nchu.edu.tw \\ 3 Innovation and Development Centre of Sustainable Agriculture (IDCSA), Department of Soil and Water \\ Conservation, National Chung Hsing University, Taichung 402, Taiwan \\ * Correspondence: scchen@nchu.edu.tw; Tel.: +886-422851558
}

Received: 29 August 2018; Accepted: 4 October 2018; Published: 10 October 2018

\begin{abstract}
Understanding the effects of riparian vegetation under sediment-laden flow is becoming crucial due to the increase in frequency of extreme weather events. This study designed three densities and nine random distributions of bent flexible vegetation in flume experiments under sediment-laden flow. Sediments were continually added to the flume at a rate of $21 \mathrm{~kg} / \mathrm{h}$ to simulate a natural river environment in a sediment-laden flow. The results showed that the evolutionary process of bed form under sediment-laden flow could be divided into four stages: scouring, development, recovery, and deposition stages, forming a dynamic cycle. Dunes were formed and backwater caused them to develop upstream, while structural resistance developed the dunes downstream. Contrary to clear water regime, sediments were deposited upstream of the vegetation area and scour occurred behind the vegetation. In addition, the vertical velocity profile showed to be dependent on the vegetation structure and four clear zones were identified: fixed, bent, canopy, and developed zones. The findings from this study provide crucial information towards river management through understanding the diverse vegetation effects under sediment-laden flows.
\end{abstract}

Keywords: sediment-laden flow; clear water regime; riparian vegetation; sediment budget

\section{Introduction}

Vegetation exists in different forms in rivers, and their existence influences flow and sediment transport dynamics and biological and other natural processes. Brown and Roshko [1], Stephan and Wychera [2], and Wang et al. [3], among several other authors [4-7], illustrated how vegetation could contribute to additional drag and lift force in rivers. These additional forces reduce the critical velocity of incipient motion for sediments, making the channel bed unstable $[3,8]$. On the contrary, stems and leaves of vegetation may reduce soil erosion [9]. Roots and underground stems may provide additional tensile strength to adsorb some insoluble colloids and organic debris [10,11]. Additionally, in river networks, vegetation may effectively reduce the resuspension of sediments and capacity of the flow [12] and delay riverbank retreat $[13,14]$. In an experiment on submerged flow over flexible vegetation, Devi and Kumar [15] illustrated a reduction of up to $16 \%$ on flow velocity measured at the upstream section as the flow reached the downstream vegetation section. Vegetation modified the curvature-induced flow patterns and the directionality of turbulent structures in an investigation by Termini [16]. The resultant cross-sectional flows influenced the bed shear stress distribution along the bend such that the peak of the bed shear stress did not reach the outer banks. 
In recent decades, climate change has altered the frequency and intensity of storms and their spatial distribution [17], leading to remarkable environmental changes such as increased sediment transfer from slope land to river channels [18], inundation, distribution and behavior of plants [19], and so forth. In addition, Schleiss, Franca, Juez, and De Cesare [12] have emphasized the pervasive role climate change has on processes related to reservoir sedimentation. Subsequently, complex interactions between floods, sediment-laden flows, and riparian vegetation is expected. It is therefore imperative to understand these interactions especially during extreme weather events. Understanding the evolution of bed forms due to such interactions would allow us to better manage sediment production and further reduce their subsequent impacts on channel networks and reservoir sedimentation.

Vegetation studies have attracted several researchers over the past decade. Through a series of flume experiments, Nepf and Vivoni [20], Ghisalberti and Nepf [21], Wilson et al. [22], Chen et al. [23] have altered vegetation densities (single or multiple), arrangements (staggered, columnar, aligned), and rigidities (rigid, flexible, or mixed). Under low vegetation density, sediments are deposited on both sides of the downstream wake to develop an open-bed form, while under high densities, the Von Kármán vortex would appear in the downstream wake and deposit sediments again to form a closed-bed form [24]. Altering vegetation arrangement in the longitudinal direction had more effect than a change in the transverse direction [23]. In their investigations on rigidity, Schlichting [25], Armanini et al. [26], Kitsikoudis et al. [27] demonstrated how bent vegetation decreased drag coefficient, erosion, and the overall disturbance on the channel bed.

The above investigations have all been carried out under clear water regime (i.e., experimental velocity less than critical velocity, and with no sediment input during the experiment). Little attention has been given to sediment-laden flows (i.e., experimental velocity greater than critical velocity, and sediment supplied in large quantities during the experiment). Henceforth, the study aims to fill this knowledge gap through laboratory experiments by investigating the interactions between floods, sediment-laden flow, and vegetation. We further explore through a sediment balance approach how changes to vegetation densities and arrangements would affect fluvial-bed morphology.

\section{Materials and Methods}

The experiments were conducted in a $15 \mathrm{~m}$ long, $0.6 \mathrm{~m}$ wide, glass-sided recirculation flume system having 0.001 slope (Figure 1). A head tank located upstream of the main channel maintained a constant water head. At the entrance of the channel, a honeycomb flow straightener was installed to steady the current. A right-angle wedge of $0.4 \mathrm{~m}$ length, $0.6 \mathrm{~m}$ width, and $0.1 \mathrm{~m}$ height was set up at $1.8 \mathrm{~m}$ from the flow straightener. An acrylic block ( $3 \mathrm{~m}$ length, $0.6 \mathrm{~m}$ width, and $0.1 \mathrm{~m}$ height) followed the wedge. Quartz sand $\left(\mathrm{SiO}_{2}\right)$ with specific mass $\varrho_{\mathrm{s}}=2.55 \mathrm{ton} / \mathrm{m}^{3}$ and median diameter $\mathrm{d}_{50}=1.22 \mathrm{~mm}$ was glued to the top of its surface to keep the same surface roughness with the channel bed. The channel bed area, $4.8 \mathrm{~m}$ length by $0.6 \mathrm{~m}$ width, was filled with quartz sand to a height of $0.1 \mathrm{~m}$. At the channel exit, a tail-water gate controlled the initial water depth to $0.1 \mathrm{~m}$. Finally, an underground water tank was used to collect water, and a recirculation pump to raise water back to the head tank, forming a closed loop. A flow discharge rate of $0.03 \mathrm{~m}^{3} / \mathrm{s}$ was set to give an initial velocity of $0.5 \mathrm{~m} / \mathrm{s}$ under no vegetation condition. This velocity was greater than the critical velocity, thus the channel was slightly eroded to simulate flooding conditions. Concurrently, quartz sand was continuously added into the flume at a rate of $0.35 \mathrm{~kg} / \mathrm{min}$ from a sand-supply device located at the entrance of the channel bed area, S-100. Each experiment lasted $9 \mathrm{~h}$. Detailed experimental parameters are shown in Table 1.

Prior to the experiments, vegetation models $(16 \mathrm{~cm}$ long) made of flexible plastic material were arranged in an area covering $2 \mathrm{~m}$ length by $0.6 \mathrm{~m}$ width. Individual vegetation models were arranged on grid points randomly determined by their $X$ and $Y$ coordinates on a $1 \mathrm{~cm} \times 1 \mathrm{~cm}$ grid system drawn at this area. These were inserted into the channel bed at an angle of about $22^{\circ}$ (between the base of the vegetation and the channel bed) such that their height was $6 \mathrm{~cm}$ with a vertical projection length of $15 \mathrm{~cm}$. Three different vegetation densities were designed: 33.33 (test 1-3), 66.67 (test 4-6), and 
100 (test 7-9) stems $/ \mathrm{m}^{2}$. Each density was triplicated, although each replicate had a different random distribution pattern as earlier described. Sediments were collected hourly from the sediment trap. They were then oven dried at $105^{\circ} \mathrm{C}$ for $48 \mathrm{~h}$ to determine the sediment budget of each experiment. From $5 \mathrm{~h}$ into the experiments, flow velocity was measured using an Ultrasound Velocity Profiler (UVP) [28]. Totally, the channel contained 135 measuring points from S-30 to S+230 as illustrated in Figure 1B. At each measuring point, 13 depths were measured at $0.5 \mathrm{~cm}$ interval, ranging from 2 to $8 \mathrm{~cm}$ below the water surface. At a measuring frequency of $20 \mathrm{~Hz}$, each velocity represented an average of 2000 measurements. The flume was then allowed to drain for topographic measurements. A high-precision scanner ( $\pm 0.5 \mathrm{~mm}$; F5, Mantis Vision) collected 45,000-point cloud data from S-150 to S+330. A time-lapse video camera (Brinno TLC200 Pro) captured (at 1 image per second) the modes of sediment transport, and how flow interacted with the vegetation.

Table 1. Experimental parameters.

\begin{tabular}{cccc}
\hline Test & Test 1-3 & Test 4-6 & Test 7-9 \\
\hline Vegetation density & $33.33 \mathrm{stems} / \mathrm{m}^{2}$ & $66.67 \mathrm{stems} / \mathrm{m}^{2}$ & 100 stems $/ \mathrm{m}^{2}$ \\
Arrangement & & Random & \\
Water discharge & $0.03 \mathrm{~m}^{3} / \mathrm{s}$ & \\
Initial velocity & $0.5 \mathrm{~m} / \mathrm{s}$ & \\
Initial water height & $0.1 \mathrm{~m}$ & \\
Froude number & 0.51 & \\
Reynolds number & 49,900 & \\
Sediment & $\mathrm{SiO} 2$ & \\
Specific mass & $2.55 \mathrm{ton} / \mathrm{m}^{3}$ \\
Grain size & $1.22 \mathrm{~mm}\left(\mathrm{D}_{50}\right)$ & \\
Solid discharge & $0.35 \mathrm{~kg} / \mathrm{min}$ & \\
Test duration & $9 \mathrm{~h}$ & \\
\hline
\end{tabular}

Note: Experimental parameters for all the tests were similar except for the vegetation density.

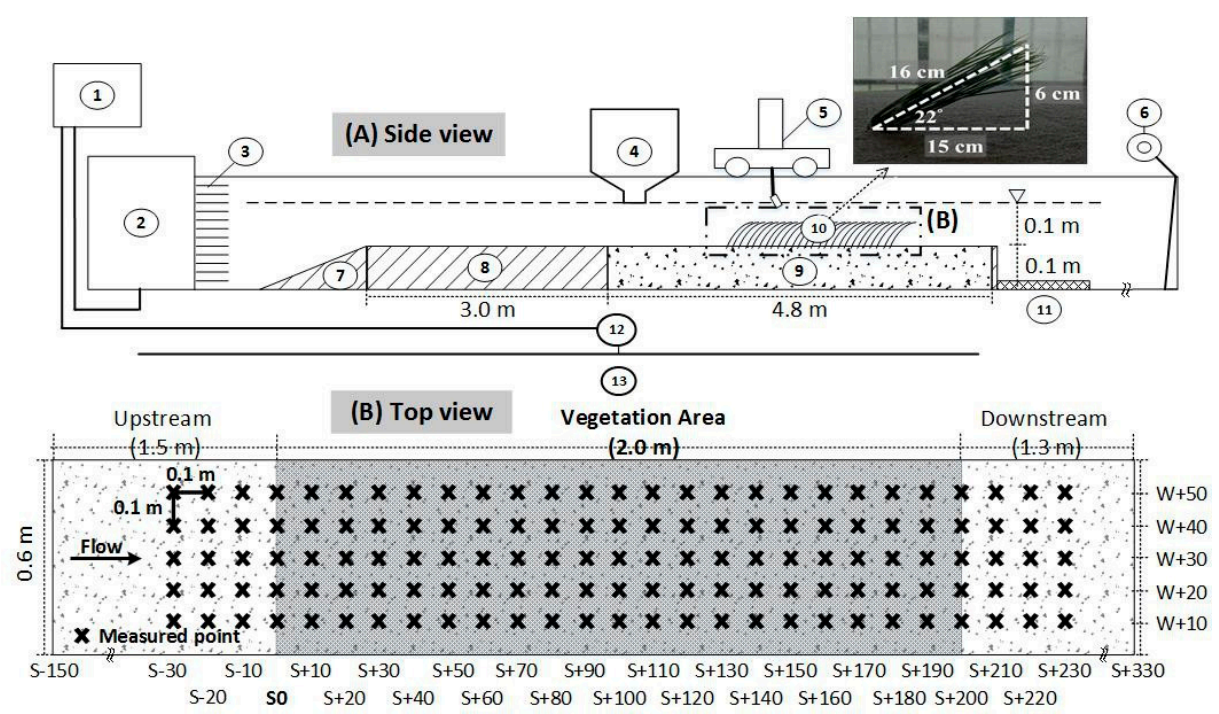

Figure 1. The flume system used for the experiments. (A) Side view of the flume system where: 1 . Head tank. 2. Water storage tank. 3. Flow straightener. 4. Sand-supply device. 5. UVP. 6. Tail-water gate. 7. Right-angle wedge. 8. Acrylic block. 9. Quartz sand area. 10. Vegetation area. 11. Sand trap. 12. Recirculation pump. 13. Underground water tank. (B) Top view of the sand bed area. Vegetation models were randomly placed in the area between S0 and S+200. X symbols represent measured points. 


\section{Results and Discussion}

\subsection{The Influence of Single Vegetation on Bed Form}

Bed evolution process around a single vegetation element could be divided into four stages: (A) scouring stage; (B) development stage; (C) recovery stage; and (D) deposition stage (Figure 2). In the scouring stage, the scour around a single vegetation element resembled that of a small pier as discussed by [29]. This was followed by the formation of a small dune behind the vegetation. Concurrently, a sand wave formed upstream and was gradually moved downstream. The development stage was mainly characterized by the gradually increasing scour depth enhanced by the continued downward jet-flow. The dune, which was uninterruptedly affected by the flowing water, developed downstream. Scour and dune volumes both increased at this stage. During the third stage, the sand wave filled the scour hole and the dune moved farther downstream. Additionally, the residual sediment deposited at the upstream end of the dune, such that a steep slope formed at the downstream end of the dune. In the final stage, the deposition stage, continuous deposit occurred farther downstream, reducing the slope of the dune at the downstream end. As a result, a single peak was formed with either sides having gentle slopes. Scouring would then occur again, forming a cycle. The existence of the sand wave marked a clear demarcation between the clear water regime and the sediment-laden flow regime. The wave formed the basis of the recovery function, and the channel bed could not reach an equilibrium stage, that is, the depth of the scour hole did not change by over 5\% in $24 \mathrm{~h}$ [30-32].

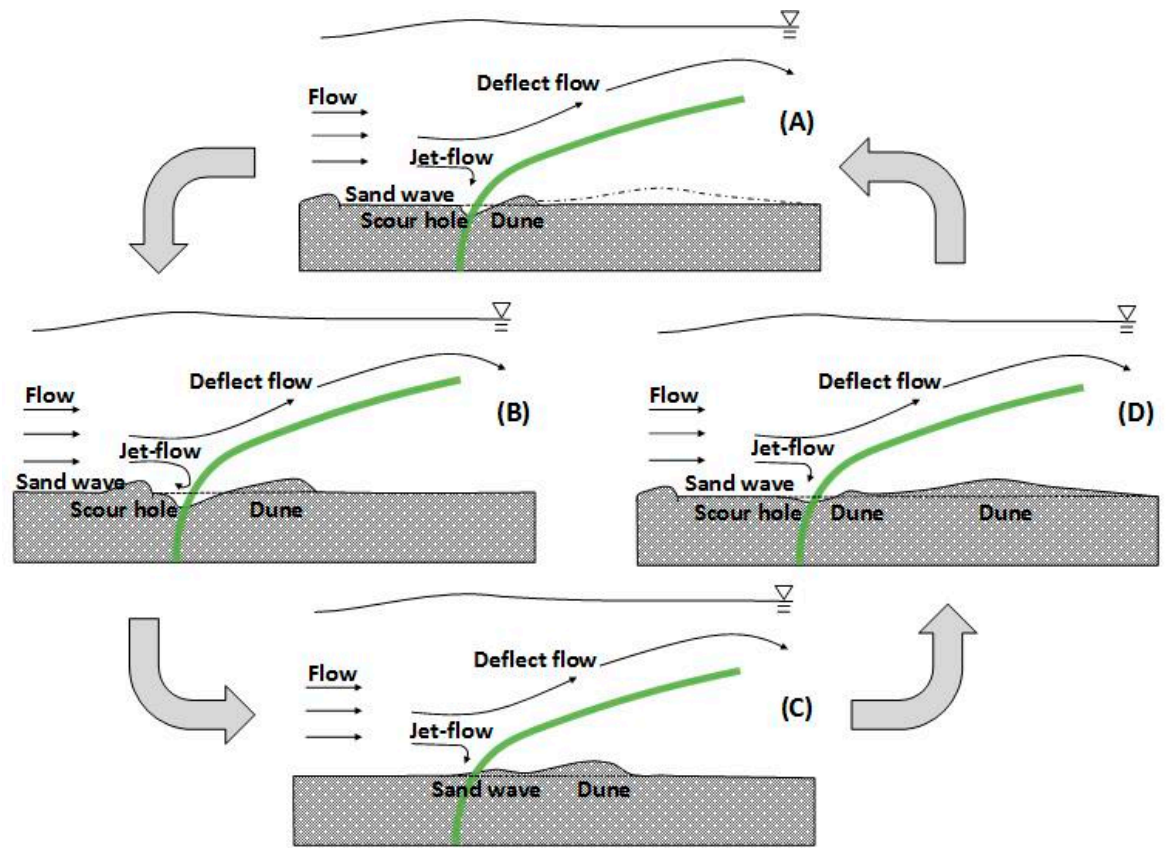

Figure 2. Schematic diagram of the sand-bed evolution. (A) Scouring stage. (B) Development stage.

(C) Recovery stage. (D) Deposition stage.

\subsection{The Influence of Vegetation Communities on Bed Form}

The final topography of the three different vegetation densities, 33.33, 66.67, and $100 \mathrm{stems} / \mathrm{m}^{2}$, were observed in the vegetation area (S0 to $\mathrm{S}+200)$. The topography of the $33.33 \mathrm{stems} / \mathrm{m}^{2}$ density is shown in Figure 3. Under this density, the cross-sectional area for water passage was not significantly reduced by the vegetation; hence, flow velocity was slightly affected in the vegetation area. Mostly sediment deposited in the vegetation area as described in Section 3.1. Shown in Figure 3 are four typical examples, representing the stages discussed in Section 3.1. Figure 3a shows the small dune behind the vegetation, Figure $3 b$ shows an enlarging dune. In Figure $3 c$, the scour hole is being filled, and finally in Figure $3 d$, sediments are transported farther downstream such that the dune becomes 
gentler. Moreover, under high vegetation density, 66 and 100 stems $/ \mathrm{m}^{2}$, the four stages explained above could not be easily observed due to the dense cover.

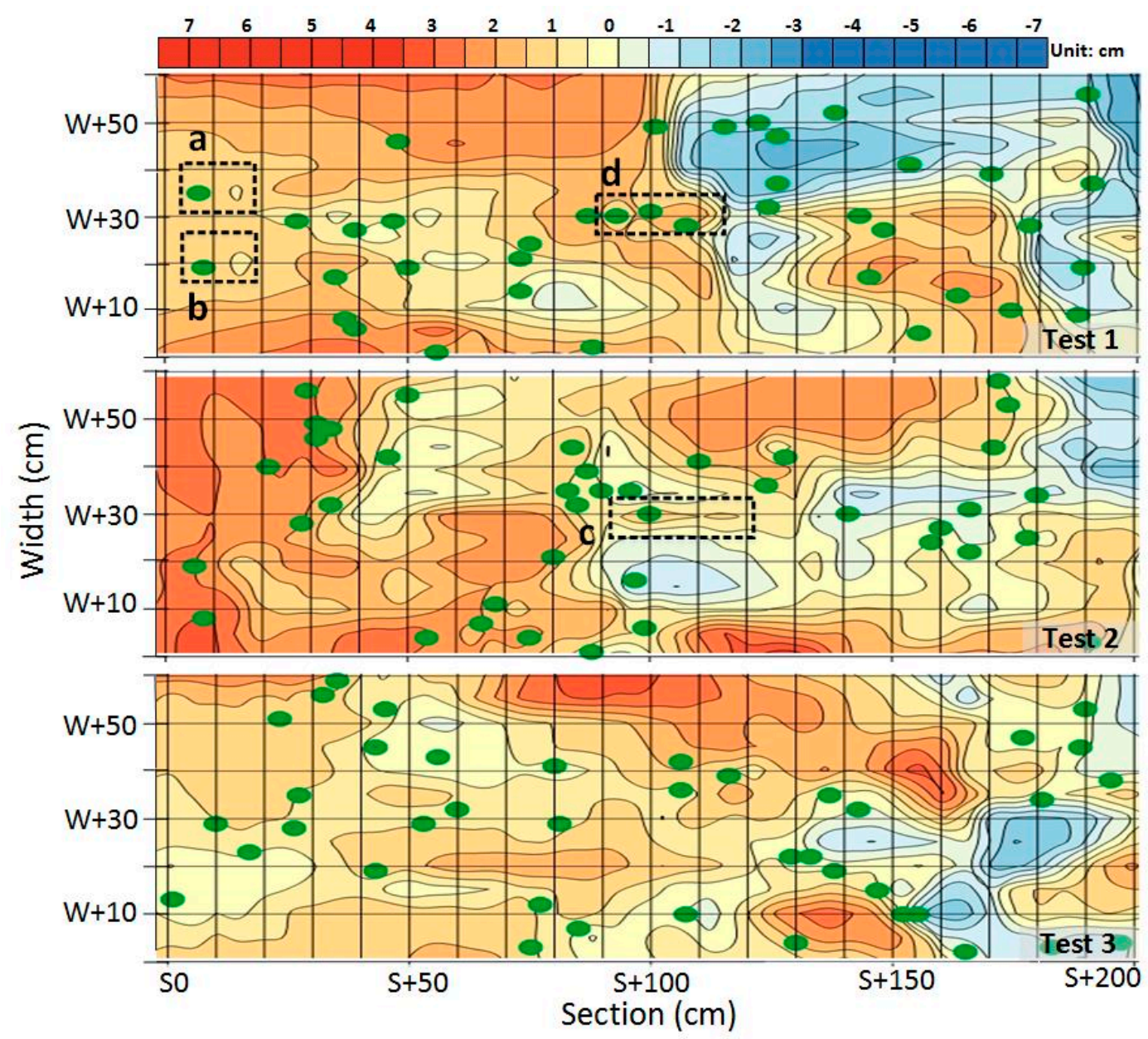

Figure 3. The contour map of channel topography after the 33.33 stems $/ \mathrm{m}^{2}$ experiments (test $1-3$ ); (a) scouring stage, (b) development stage, (c) recovery stage, (d) deposition stage. Green dots represent vegetation.

In the 66.67 stems $/ \mathrm{m}^{2}$ experiments (test $4-6$ ), the erosive and depositional topographies were halved (Figure 4). Vegetation easily blocked the incoming flow, producing backwater in some selected areas, especially those with higher density. The backwater was characterised by the regions of low velocity. Investigations by Jin et al. [33] and Naoko et al. [34] also illustrated how low velocity promoted sediment deposition, while the opposing direction of flow did not transfer the deposited sediments along the normal flow direction. Consequently, backwater deposited sediments in the direction of backwater. From the vertical velocity profile in Figure 4A, the backwater appeared at locations a (S+50, $\mathrm{W}+40), \mathrm{b}(\mathrm{S}+90$ to $110, \mathrm{~W}+40)$, and $\mathrm{c}(\mathrm{S}+110$ to $130, \mathrm{~W}+40)$. These locations were then plotted in the contour map (Figure 4B). A sandbar larger than the dune developed above and gradually developed upstream in the location having backwater. The $\mathrm{x}$ and solid arrows in the figure represent the locations where the sandbar developed upstream and the possible flow direction, respectively. 

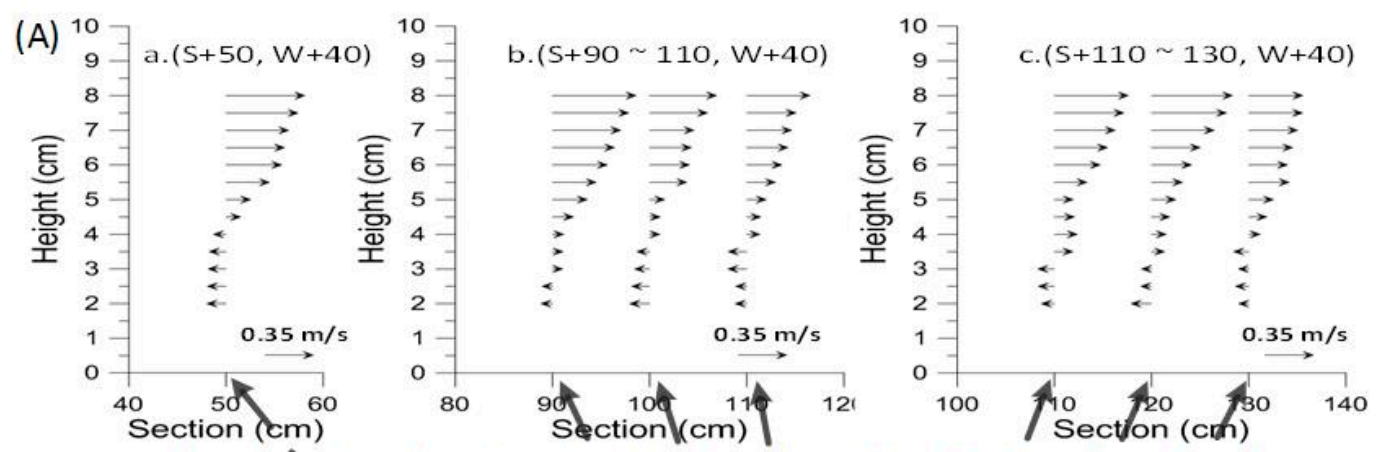

(B)
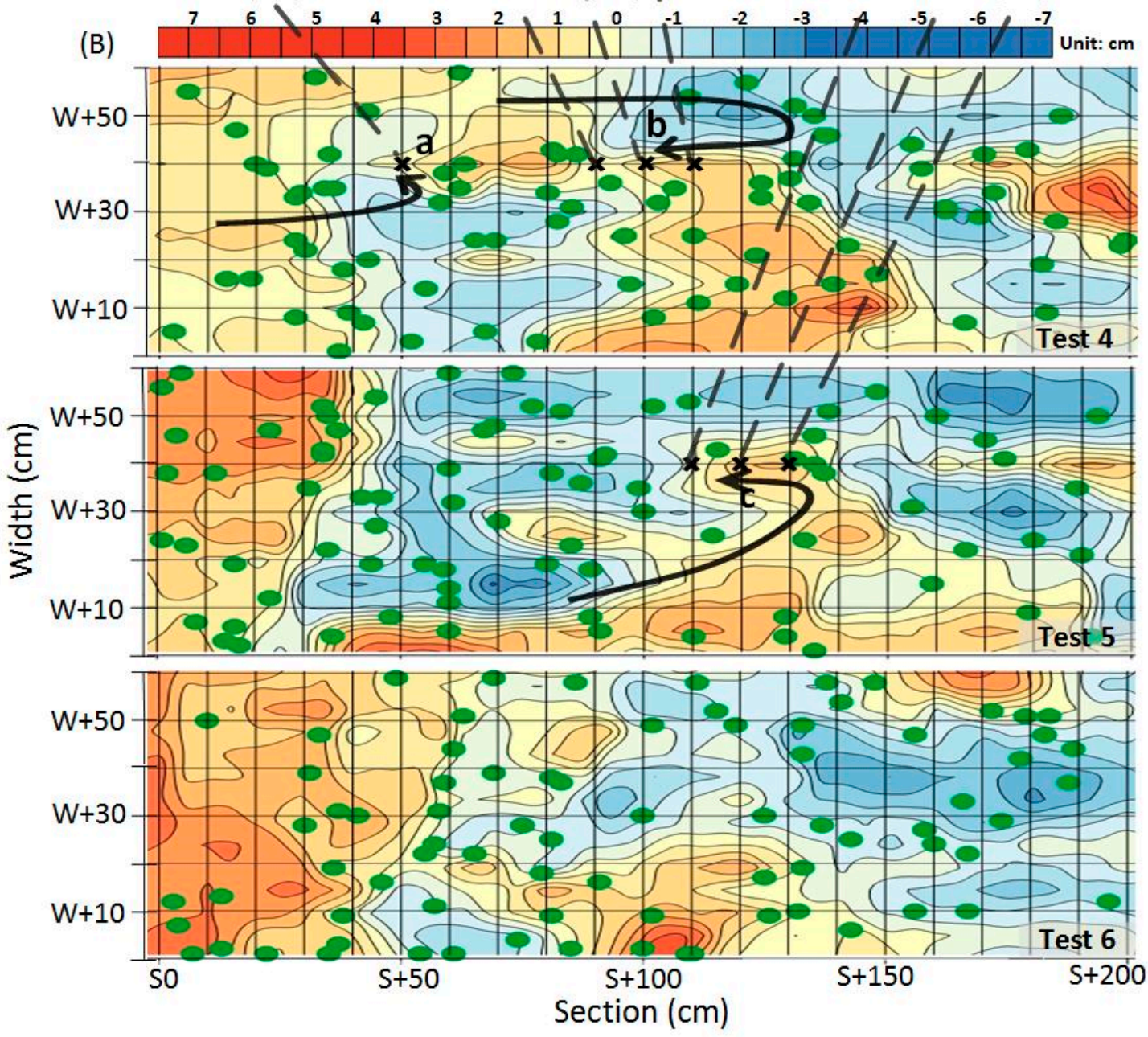

Figure 4. (A) The vertical velocity profile of backwaters at measuring points a $(S+50, W+40), b(S+90$ to $110, \mathrm{~W}+40)$, c $(\mathrm{S}+110$ to $130, \mathrm{~W}+40)$. (B) The contour map of channel topography after the 66.67 stems $/ \mathrm{m}^{2}$ experiments (test $4-6$ ). Green dots represent vegetation.

The highly dense vegetation, 100 stems $/ \mathrm{m}^{2}$, greatly blocked the incoming flow (Figure 5), such that the channel bed indicated an erosive pattern due to the constricted passage between vegetation elements. Vegetation elements further interacted with each other under this density, thus complicating the interactions between the sediment-laden flow and the vegetation elements. Dense vegetation communities provided lots of structural resistances to create slow-flow zones, whose velocity profiles are shown on Figure 5, where suspended sediment settled and existing sediment was protected from erosion [35]. Therefore, we could find more deposition formed a large dune, which gradually extended downstream. From the above results, the net effects on the channel bed were uncertain, as several counteractive forces influenced each other in the vegetation area. Moreover, 
two significant mechanisms influenced the final topography: the constriction (which enhanced erosion) and the blockage effects (which enhanced deposition). When the blockage effect was greater than the constriction effect, there was mainly deposition (Figure 3). Conversely, when the constriction effect was greater than the blockage effect, there was mainly erosion (Figure 5). In addition, the direction of the dune was dependent on its formation: a dune caused by backwater developed upstream (Figure 4), while that caused by structural resistance developed downstream (Figure 5). The reader should note that our vegetation elements had no roots; hence, the effects of roots are not discussed.

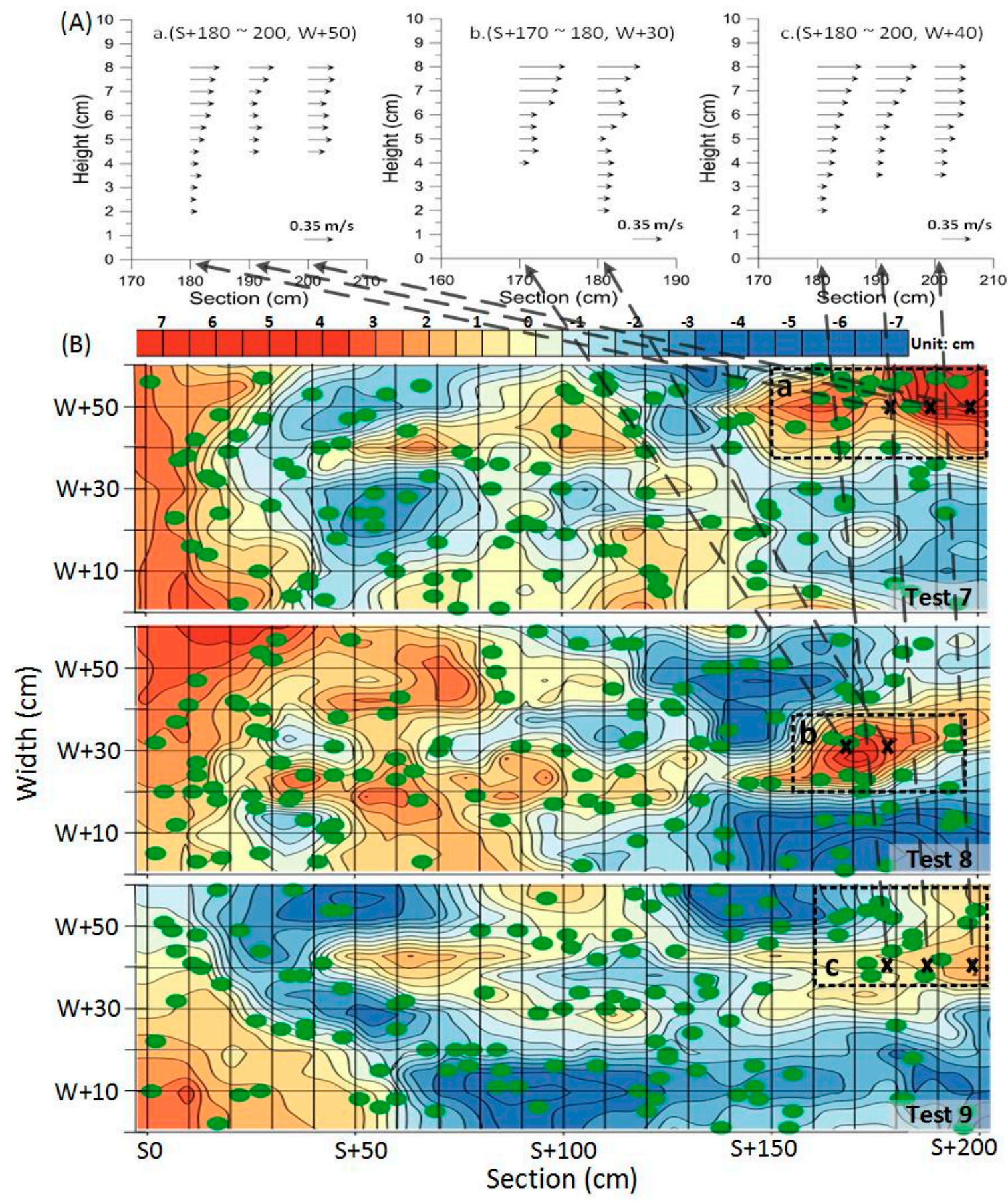

Figure 5. (A) The vertical velocity profile of low-velocity area at measuring points a (S+180 to 200, $\mathrm{W}+50), \mathrm{b}(\mathrm{S}+170$ to $180, \mathrm{~W}+30), \mathrm{c}(\mathrm{S}+180$ to $200, \mathrm{~W}+40)$. (B) The contour map of channel topography after the $100 \mathrm{stems} / \mathrm{m}^{2}$ experiments (test 7-9). Green dots represent vegetation. 


\subsection{The Influence of Vegetation on Sediment Budget in Spatial and Time Distribution}

Sediments were collected on an hourly basis, oven dried at $105{ }^{\circ} \mathrm{C}$ for $48 \mathrm{~h}$, and were then weighed to determine the sediment budget of the entire channel. The sediment budget was the designed sediment supplement $(21 \mathrm{~kg} / \mathrm{h}$ ) minus the hourly collected sediments. Hence, a positive value indicated deposition, while a negative represented erosion. The average amount of hourly sediment budget per density is shown in Figure 6. Major erosion always occurred within $3 \mathrm{~h}$ into the experiments. The period between 3 and $6 \mathrm{~h}$ constituted the development and recovery stage, while beyond $6 \mathrm{~h}$ was the deposition stage. The total sediment budget was $5.31,-10.89$, and $-17.28 \mathrm{~kg}$ in $33.33,66.67$, and 100 stems $/ \mathrm{m}^{2}$ experiments, respectively. This indicates that the entire channel under 33 stems $/ \mathrm{m}^{2}$ was characterized by deposition, while erosion dominated the other densities. The severity of erosion increased with increasing vegetation density.

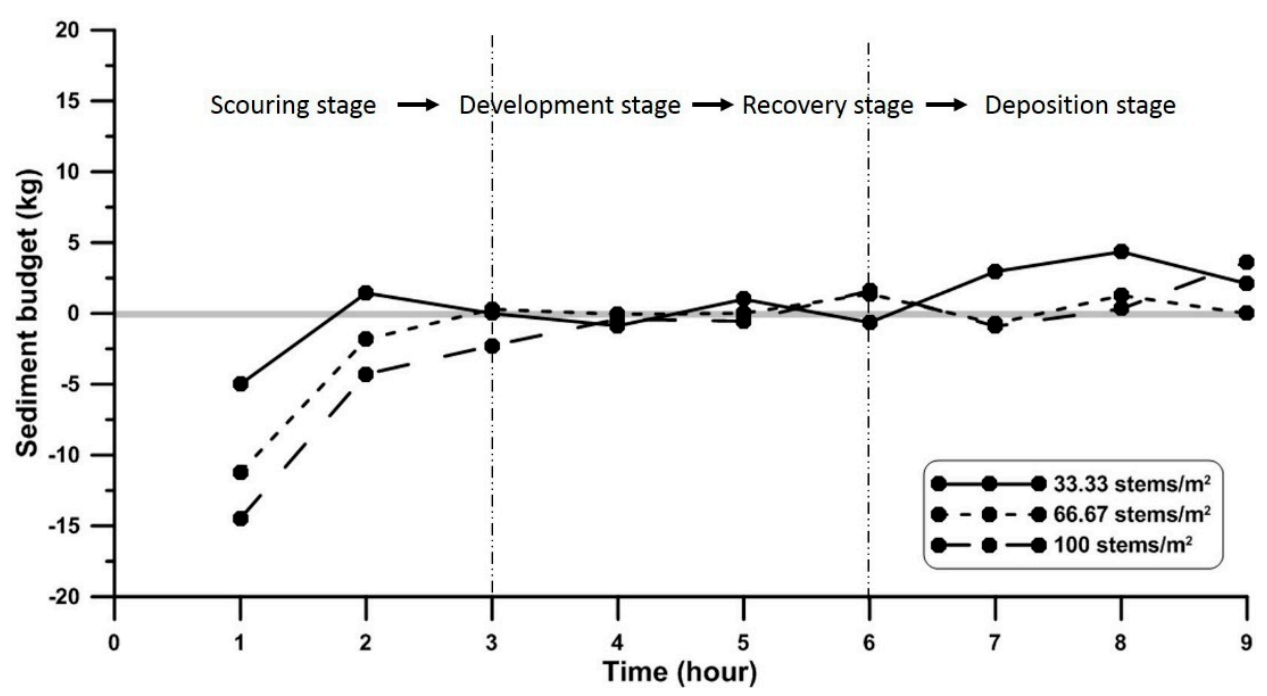

Figure 6. Average amount of hourly sediment budget in $33.33,66.67,100$ stems $/ \mathrm{m}^{2}$ experiments.

The flume was then partitioned into three regions: the upstream area (S-150 to S0), the vegetation area (S0 to $S+200)$, and the downstream area (S+200 to $S+330)$ to discuss the influence of vegetation on sediment budget in different areas. Sediment volumes between the initial and final channel topography were converted to sediment weights and compared. The sediment budget in these areas is shown in Table 2. The upstream area was dominated by deposition due the impediment effect. During the initial flow obstruction, part of the kinetic energy was converted to potential energy, thus reducing flow velocity while water level increased. These activities promoted sediment deposition and a depositional topography. Similarly, the vegetation area was dominated by deposition under the 33.33 and $66.67 \mathrm{stems} / \mathrm{m}^{2}$ densities and erosion in the $100 \mathrm{stems} / \mathrm{m}^{2}$ density. Based on this pattern, we could speculate that the constriction effect gradually increased and finally surpassed the block effects as vegetation increased in the vegetation area. That also meant a transition from deposition to erosion as vegetation increased in the vegetation area. At the downstream area, all densities indicated negative sediment budgets. This is attributed to the deflected flow from the vegetation area, which scoured the channel bed. An interesting observation is the nonsignificant difference between the 33.33 and $66.67 \mathrm{stems} / \mathrm{m}^{2}$ densities. We attribute this to the fact that in the vegetation area, the channel was depositional; hence, at the downstream area, the channel bed was only affected by the deflected flow. The 100 stems $/ \mathrm{m}^{2}$ density was eroded in the vegetation area. Instead of eroding further at the downstream area, the process was slowed due to sediment eroded from the vegetation area.

From the above observations, sediment budget under the sediment-laden flow was depositional while scour occurred behind the vegetation element. This differed from the clear water scour regime, which showed the opposite $[24,32]$. The contradicting observation was caused by the sediment 
supplied upstream, which would be deposited in front of the vegetation due to the impediment effect. Moreover, the sediments deposited behind the vegetation under the clear water regime could not remain deposited under the sediment-laden flow since the flow velocity was greater than the critical velocity. Hence, the deposited sediments would be transferred farther downstream. Additionally, the deflected flow scoured the channel bed under the sediment-laden flow. A comparison of the clear water regime and the sediment-laden flow is illustrated in Figure 7.

Table 2. Average amounts of sediment budget in different regions.

\begin{tabular}{cccc}
\hline Density $\left(\right.$ Stems $\left./ \mathbf{m}^{\mathbf{2}}\right)$ & Upstream Area $\left(\mathbf{k g} / \mathbf{m}^{\mathbf{2}}\right)$ & Vegetation Area $\left(\mathbf{k g} / \mathbf{m}^{\mathbf{2}}\right)$ & Downstream Area $\left(\mathbf{k g} / \mathbf{m}^{\mathbf{2}}\right)$ \\
\hline 33.33 & +5.57 & +25.43 & -38.28 \\
66.67 & +17.22 & +1.19 & -35.63 \\
100.00 & +31.31 & -24.38 & -20.81 \\
\hline
\end{tabular}

Note: + mean deposition; - mean erosion; upstream area is from S-150 to S0, vegetation area is from S0 to S+200, downstream area is from $\mathrm{S}+200$ to $\mathrm{S}+330$.

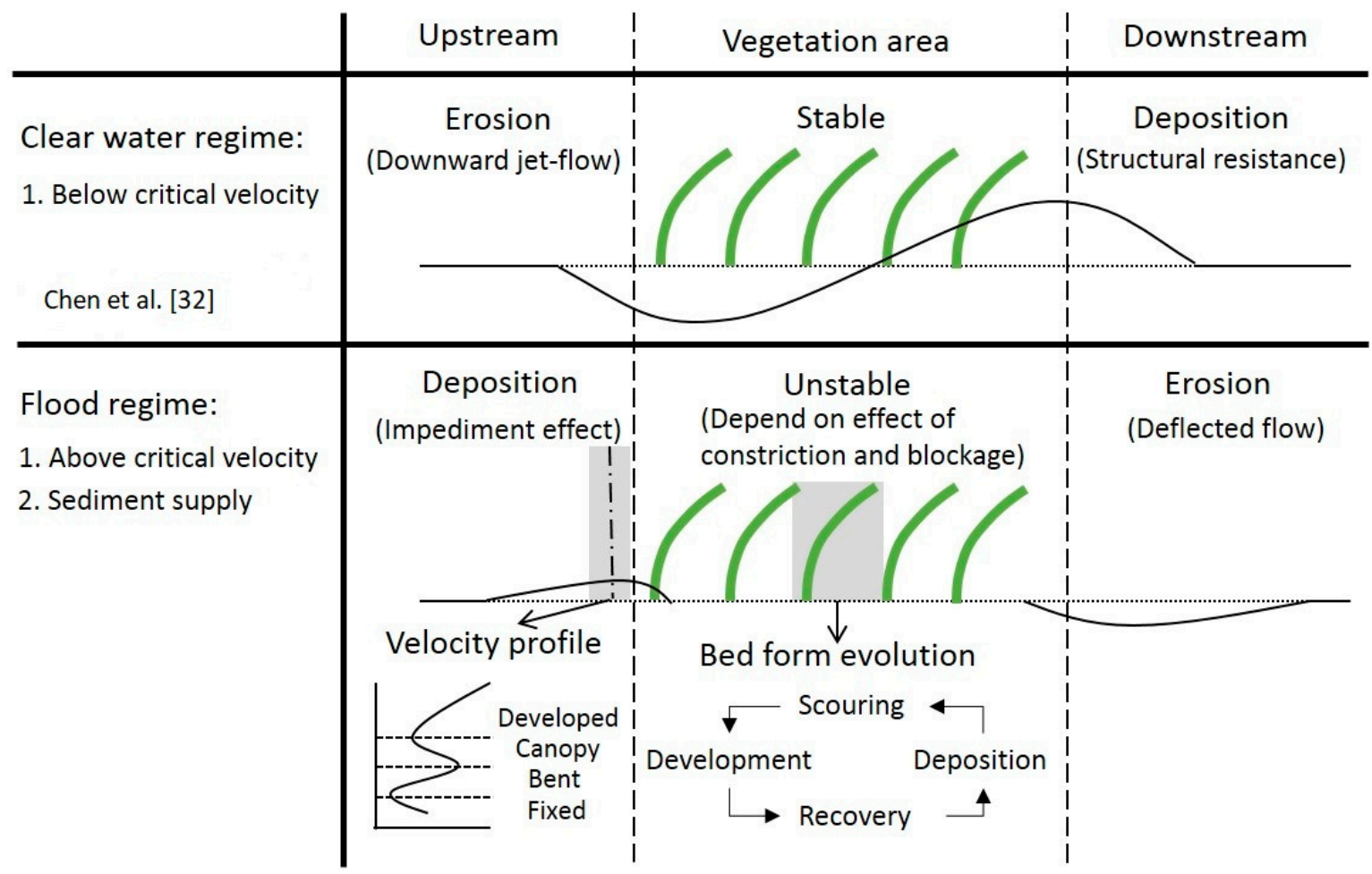

Figure 7. Schematic diagram of the clear water and sediment-laden flow.

\subsection{The Influence of Vegetation on Velocity Profile and Turbulent Kinetic Energy}

To gain more insight into the depositional circumstance in front of the vegetation area, we chose a central measured line $(W+30)$ to avoid wall effects and a closest measured point $(S-10, W+30)$ to the vegetation area to draw the vertical velocity profile and for computing the turbulent kinetic energy (TKE). The velocity profile of the 33.33 stems $/ \mathrm{m}^{2}$ density resembled that of steady flow (Figure $8 \mathrm{~B}$ ). This suggests that the velocity in the upstream area was not influenced by the vegetation elements.

Velocity profile changed obviously in the 66.67 stems $/ \mathrm{m}^{2}$ density and is marked by three turning points at the heights of $2.5,4$, and $5 \mathrm{~cm}$. Velocity decreased at the height of 2 to $2.5 \mathrm{~cm}$, increased at the height of 2.5 to $4 \mathrm{~cm}$, then decreased again at the height of $4 \mathrm{~cm}$ to $5 \mathrm{~cm}$, and increased significantly beyond $5 \mathrm{~cm}$ (Figure $8 \mathrm{C}$ ). Shown in the figure is a denser and fixed structure in the region of 2 to $2.5 \mathrm{~cm}$; hence, the flow was impeded, causing flow deceleration at this zone. Vegetation structure was bent at the height of 2.5 to $4 \mathrm{~cm}$; hence, the water could flow along the bent structure, resulting in accelerated 
flow. Vegetation was sparse and delicate at the height of 4 to $5 \mathrm{~cm}$, which corresponded also to the zone of vegetation canopy. It was easily fluctuated by water flow to absorb the flow kinetic energy, thus decelerating the flow. Beyond $5 \mathrm{~cm}$, flow no longer interacted with the vegetation such that it accelerated into a fully developed state.

The velocity profile of the 100 stems $/ \mathrm{m}^{2}$ density did not deviate much from the $66.67 \mathrm{stems} / \mathrm{m}^{2}$. Notable differences were the turning points, which rose to $3.5,5$, and $6 \mathrm{~cm}$ in the former experiments (Figure 8D). The abundance of the dense and fixed structure resulted in the extension of the fixed zone to a height of $2 \mathrm{~cm}$ to $3.5 \mathrm{~cm}$.
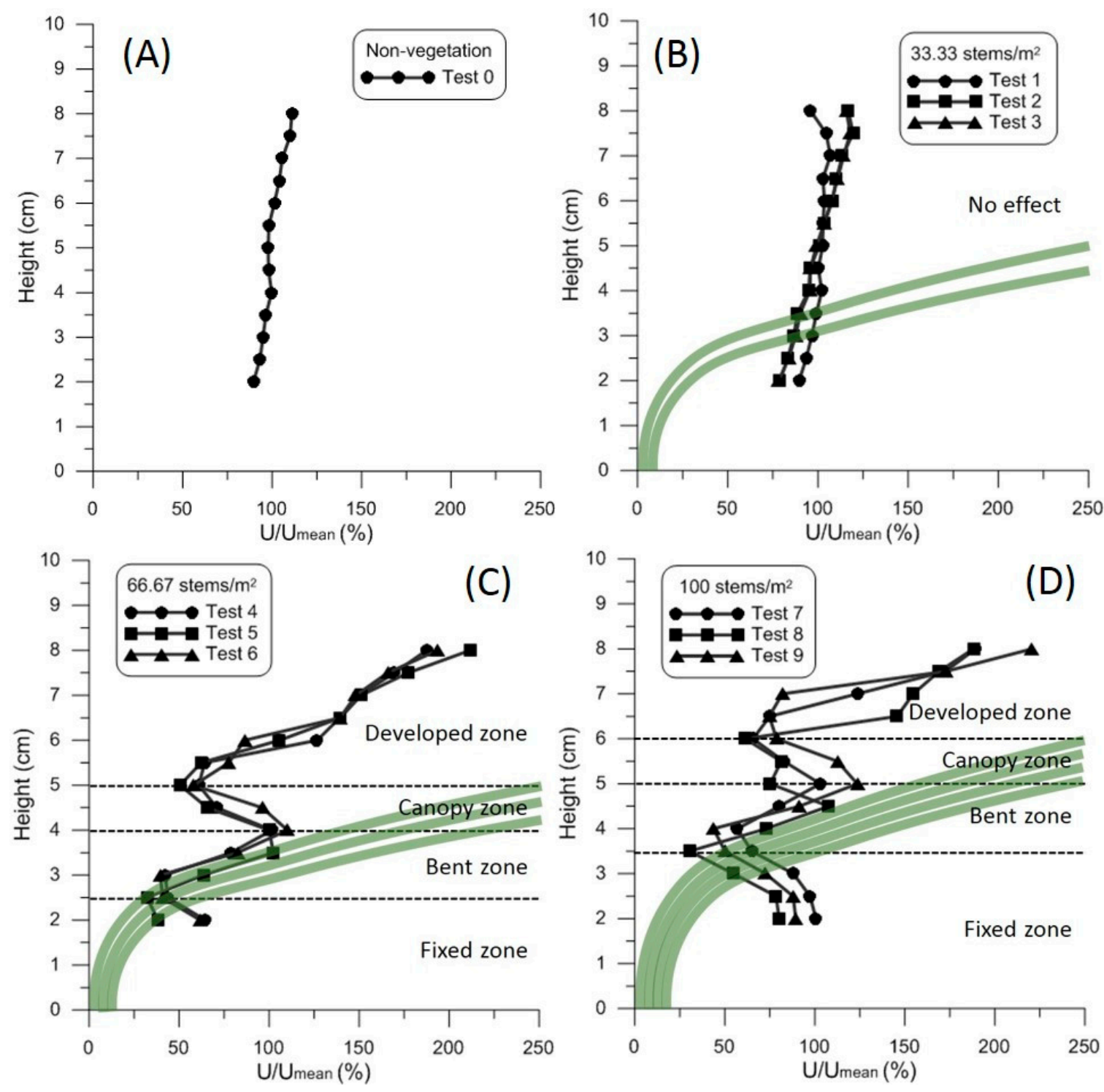

Figure 8. The relationship between the vertical velocity profile and vegetation elements in each vegetation density experiment. (A) is no vegetation test, (B) is $33.33 \mathrm{stems} / \mathrm{m}^{2}$ test, $(\mathbf{C})$ is $66.67 \mathrm{stems} / \mathrm{m}^{2}$ test, (D) is 100 stems $/ \mathrm{m}^{2}$ test.

Under the three density experiments, minimum velocity always took place in the bottom layer and was reduced by $83 \%, 39 \%$, and $30 \%$ in the 33.33, 66.67, and 100 stems $/ \mathrm{m}^{2}$ experiments, respectively. This led to an increase in the sediment deposited: $5.57,17.22$, and $31.31 \mathrm{~kg} / \mathrm{m}^{2}$ in the $33.33,66.67$, and 100 stems $/ \mathrm{m}^{2}$ experiments, respectively. Decelerated flow occurred at the canopy zone which separated the water and vegetation. When water flows through an interface with two dissimilar materials, it easily generates Kelvin-Helmholtz vortices to create turbulence and reduce velocity [1]. 
This observation is further validated in Figure 9, where the variation of TKE is illustrated. TKE is defined as the following:

$$
T K E=\frac{1}{2}\left({u^{\prime}}^{2}+v^{\prime 2}+w^{\prime 2}\right)
$$

where $u^{\prime}, v^{\prime}$, and $w^{\prime}$ are turbulent velocity components in $x, y$, and $z$ direction, respectively. We assumed $v^{\prime}$ and $w^{\prime}$ to be zero due to the limitation of the UVP (which is a one-dimensional velocity instrument). $u^{\prime}=u-\bar{u}$, where $\bar{u}$ is mean velocity.
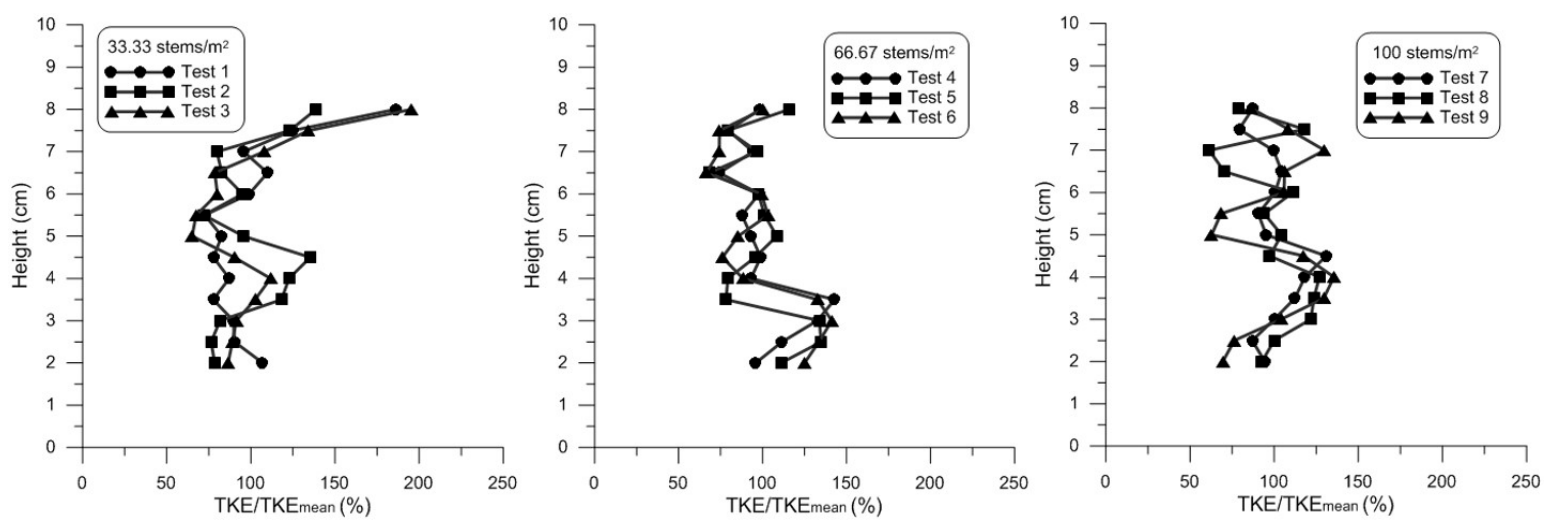

Figure 9. Turbulent kinetic energy variation under the different densities.

Maximum TKE is seen at the top layer, suggesting a slight to no influence from vegetation. The maximum TKE was from the water wave at the surface. On the contrary, the two other densities had their maximum TKE at the bottom, suggesting vegetation influence. Therefore, the decreased velocity was not simply caused by the sparse and delicate vegetation structure at this zone. The results fit an observation made by [36] who found the maximum Reynolds to occur around the vegetation canopy and that of [23] who found the maximum turbulence intensity to occur at 0.9-1.2 times the vegetation height.

\section{Practical Implications}

Sediment budgets are of paramount importance in fluvial studies as they reveal crucial information on how river channels would respond to specific modifications. Based on reviewed literature, such as [12,37], sediment availability alters sediment fluxes. Henceforth, changing the spatial distribution of vegetation (e.g., vegetation density) could amplify the sediment flux variation and undesirable consequences may result downstream, such as lack of sediment supply. Observations made from our experiments suggest that sediment budget could be governed in part by modifying vegetation density.

On another implication, vegetation communities bolster the ecological environment. However, the gradual development of vegetation may reduce the channel width. This may subsequently worsen the impact of floods. Driftwood nearby and along river banks may then be introduced in the channel to destroy hydraulic structures [38]. Regular modification or clearing the waterfront of vegetation is necessary, yet complete removal needs to be avoided to preserve the natural environment. Therefore, critical assessment of the vegetation density is necessary when rehabilitating fluvial environments

\section{Conclusions}

Flume experiments were used to investigate the interactions between floods, vegetation, and sediments (sediment-laden flow). Findings were then compared to a clear water regime. Significant and consistent differences existed between the two regimes. A more pronounced observation was the deposition in front of vegetation elements under the sediment-laden flow, while scour occurred behind. Based on other studies of clear water regime, scour occurred in front of the vegetation while deposition 
was behind. A sand wave in the sediment-laden flow resulted in four stages: scouring, development, recovery, and deposition stages, after which scouring occurred again to form a complete dynamic cycle. Bed evolution, moreover, under clear water regime would not form a cycle since with time an equilibrium state is attained. Bed form was found to be uncertain under the sediment-laden flow. Nonetheless, it was observed to be dependent on the constriction and block effects. Finally, the velocity profile in front of the vegetation was significantly influenced by the vegetation structure. The profile could be divided into four zones: fixed, bent, canopy, and developed zones from the bottom to top based on their turning points. Under low vegetation densities, maximum TKE is from waves generated at the water surface, while increased density shifted the location of maximum TKE towards the bottom due to vegetation structure interactions. Since the spatial distribution of vegetation elements was purely random, further investigations are necessary to validate the experiment. Adding sediments at different rates and location, not only at the channel entrance, could enhance our understanding of vegetation and sediment-laden flow interactions.

Author Contributions: Conceptualization and methodology, and draft preparation, J.-F.L.; paper review, S.S.T.; supervision, S.-C.C.

Funding: This research was funded by the Ministry of Science and Technology under the grant MOST 104-2313-B-005-034-MY3, and Ministry of Education under the Higher Education Sprout Project.

Acknowledgments: The authors are thankful to the anonymous reviewers of this work.

Conflicts of Interest: The authors declare no conflict of interest.

\section{References}

1. Brown, G.L.; Roshko, A. On density effects and large structure on turbulent mixing layer. J. Fluid Mech. 1974, 64, 775-816. [CrossRef]

2. Stephan, U.; Wychera, U. Analysis of flow velocity fluctuations in different macrophyte banks in a natural open channel. In Proceedings of the Symposium Ecohydraulics 2000, Quebec City, QC, Canada, 11-14 June 1996.

3. Wang, H.; Tang, H.W.; Zhao, H.Q.; Zhao, X.Y.; Lü, S.Q. Incipient motion of sediment in the presence of submerged flexible vegetation. Water Sci. Eng. 2015, 8, 63-67. [CrossRef]

4. Rominger, J.T.; Lightbody, A.F.; Nepf, H.M. Effects of added vegetation on sand bar stability and stream hydrodynamics. J. Hydraul. Eng. ASCE 2010, 136, 994-1002. [CrossRef]

5. Liu, C.; Hu, Z.; Lei, J.; Nepf, H. Vortex structure and sediment deposition in the wake behind a finite patch of model submerged vegetation. J. Hydraul. Eng. 2018, 144, 04017065. [CrossRef]

6. Liu, X.G.; Zeng, Y.H. Drag coefficient for rigid vegetation in subcritical open channel. Procedia Eng. 2016, 154, 1124-1131. [CrossRef]

7. Liu, X.; Zeng, Y. Drag coefficient for rigid vegetation in subcritical open-channel flow. Environ. Fluid Mech. 2017, 17, 1035-1050. [CrossRef]

8. Wu, T.H.; Wang, H.; Liang, D.F.; Lv, S.Q.; Yan, J. Incipient motion of sediment in the presence of emergent rigid vegetation. J. Hydro-Environ. Res. 2013, 7, 202-208.

9. Church, M. Geomorphic thresholds in riverine landscapes. Freshw. Biol. 2002, 47, 541-557. [CrossRef]

10. Pollen-Bankhead, N.; Simon, A.; Jaeger, K.; Wohl, E. Destabilization of streambanks by removal of invasive species in canyon de chelly national monument, arizona. Geomorphology 2009, 103, 363-374. [CrossRef]

11. Xu, H.W.; Lu, Y. Research advances of aquatic plants in water ecological restoration. Chin. Agric. Sci. Bull. 2011, 27, 413-416.

12. Schleiss, A.J.; Franca, M.J.; Juez, C.; De Cesare, G. Reservoir sedimentation. J. Hydraul. Res. 2016, 54, 595-614. [CrossRef]

13. Horppila, J.; Nurminen, L. The effect of an emergent macrophyte (typha angustifolia) on sediment resuspension in a shallow north temperate lake. Freshw. Biol. 2001, 46, 1447-1455. [CrossRef]

14. Horppila, J.; Nurminen, L. Effects of submerged macrophytes on sediment resuspension and internal phosphorus loading in lake hiidenvesi. Water Res. 2003, 37, 4468-4474. [CrossRef] 
15. Devi, T.B.; Kumar, B. Experimentation on submerged flow over flexible vegetation patches with downward seepage. Ecol. Eng. 2016, 91, 158-168. [CrossRef]

16. Termini, D. Experimental analysis of the effect of vegetation on flow and bed shear stress distribution in high-curvature bends. Geomorphology 2016, 274, 1-10. [CrossRef]

17. Chen, C.-N.; Tfwala, S. Impacts of climate change and land subsidence on inundation risk. Water 2018, 10, 157. [CrossRef]

18. Zhou, Y.; Xu, Y.; Xiao, W.; Wang, J.; Huang, Y.; Yang, H. Climate change impacts on flow and suspended sediment yield in headwaters of high-latitude regions-A case study in china's far northeast. Water 2017, 9, 966. [CrossRef]

19. Termini, D.; Di Leonardo, A. Turbulence structure and implications in exchange processes in high-amplitude vegetated meanders: Experimental investigation. Adv. Water Resour. 2018, 120, 114-127. [CrossRef]

20. Nepf, H.M.; Vivoni, E.R. Flow structure in depth-limited, vegetated flow. J. Geophys. Res. Oceans 2000, 105, 28547-28557. [CrossRef]

21. Ghisalberti, M.; Nepf, H.M. Mixing layers and coherent structures in vegetated aquatic flows. J. Geophys. Res. Oceans 2002, 107. [CrossRef]

22. Wilson, C.A.M.E.; Stoesser, T.; Bates, P.D.; Batemann, P.A. Open channel flow through different forms of submerged flexible vegetation. J. Hydraul. Eng. 2003, 129, 847-853. [CrossRef]

23. Chen, S.C.; Kuo, Y.M.; Li, Y.H. Flow characteristics within different configurations of submerged flexible vegetation. J. Hydrol. 2011, 398, 124-134. [CrossRef]

24. Follett, E.M.; Nepf, H.M. Sediment patterns near a model patch of reedy emergent vegetation. Geomorphology 2012, 179, 141-151. [CrossRef]

25. Schlichting, H. Boundary Layer Theory, 10th ed.; Springer: Berlin, Germany, 2000.

26. Armanini, A.; Righetti, M.; Grisenti, P. Direct measurement of vegetation resistance in prototype scale. J. Hydraul. Res. 2005, 45, 481-487. [CrossRef]

27. Kitsikoudis, V.; Kirca, V.S.O.; Yagci, O.; Celik, M.F. Clear-water scour and flow field alteration around an inclined pile. Coast. Eng. 2017, 129, 59-73. [CrossRef]

28. Met-Flow. Ultrasound Velocity Profiler, Uvp-Duo User's Guide; Met-Flow SA: Lausanne, Switzerland, 2006.

29. Dey, S. Time-variation of scour in the vicinity of circular piers. Proc. Inst. Civ. Eng. Water Marit. Energy 1999, 136, 67-75. [CrossRef]

30. Bijan, D. Controlling mechanism of local scouring. J. Hydraul. Eng. 1990, 116, 1197-1214.

31. Melville, B.W.; Coleman, S.E. Bridge Scour; Water Resources Publications, LLC: Littleton, CO, USA, 2000.

32. Chen, S.C.; Chan, H.C.; Li, Y.H. Observations on flow and local scour around submerged flexible vegetation. Adv. Water Resour. 2012, 43, 28-37. [CrossRef]

33. Jin, Z.W.; Lu, J.Y.; Wu, H.L. Study of bedload transport in backwater flow. J. Hydrodyn. 2016, $28,153-161$. [CrossRef]

34. Naoko, N.; Sumiko, K.; Toshihiko, S.; Shinji, E. Sediment accumulation owing to backwater effect in the lower reach of the stung sen river, cambodia. Geomorphology 2017, 296, 182-192.

35. Rood, S.B.; Goater, L.A.; Gill, K.M.; Braatne, J.H. Sand and sandbar willow: A feedback loop amplifies environmental sensitivity at the riparian interface. Oecologia 2011, 165, 31-40. [CrossRef] [PubMed]

36. Nezu, I.; Sanjou, M. Turbulence structure and coherent motion in vegetated canopy open-channel flows. J. Hydro-Environ. Res. 2008, 2, 62-90. [CrossRef]

37. Juez, C.; Hassan, M.A.; Franca, M.J. The origin of fine sediment determines the observations of suspended sediment fluxes under unsteady flow conditions. Water Resour. Res. 2018, 54, 5654-5669.

38. Nardin, W.; Edmonds, D.A.; Fagherazzi, S. Influence of vegetation on spatial patterns of sediment deposition in deltaic islands during flood. Adv. Water Resour. 2016, 93, 236-248. [CrossRef]

(C) 2018 by the authors. Licensee MDPI, Basel, Switzerland. This article is an open access article distributed under the terms and conditions of the Creative Commons Attribution (CC BY) license (http:/ / creativecommons.org/licenses/by/4.0/). 